\section{Case Reports in Dermatology}

(C) 2016 The Author(s)

Published by S. Karger AG, Basel www.karger.com/cde

\title{
Inframammary Dermatitis: A Case of Localized Late-Onset Darier's Disease
}

\author{
Dennis Linder ${ }^{\mathrm{a}} \quad$ Elena Marinello $^{\mathrm{b}} \quad$ Pietro Maria Donisi ${ }^{\mathrm{c}}$ \\ Roberto Salmaso ${ }^{d}$ Edoardo Zattra ${ }^{b}$ Anna Zampetti ${ }^{\mathrm{e}}$
}

${ }^{a}$ Section of Biostatistics, University of Oslo, Oslo, Norway; ${ }^{b}$ Dermatology Unit, University of Padua, Padua, Italy; 'Pathology Department, 'SS. Giovanni e Paolo' Hospital, Venice, Italy; ${ }^{d}$ Pathology Unit, University of Padua, Padua, Italy; ${ }^{\mathrm{e}}$ Rare Diseases and Periodic Fevers Research Centre, Department of Internal Medicine, Rome, Italy

\section{Keywords}

Adapalene · ATP2A2 gene · Corticosteroids · Darier-White disease · Genodermatoses . Retinoids

\section{Abstract}

Darier's disease (DD) is an autosomal dominant inherited genodermatosis which is often under- or misdiagnosed. In the majority of cases, the disease manifests in adolescents or young adults with small brownish-yellow, warty, hyperkeratotic papules in multiple seborrheic areas of the body. Localized DD (LDD) is a clinical variant, first described by Kreibich in 1906; only a few cases are reported in the literature. We described the case of an aged woman presenting with LDD, and we review the literature on this subject.

(C) 2016 The Author(s)

Published by S. Karger AG, Basel

\section{Case Report}

A 71-year-old woman presented with several symmetrically distributed, small, very itchy, partly excoriated red papules surrounded by an erythematous halo in the infra- 
mammary and presternal area. The lesions - approximately 4-8 $\mathrm{mm}$ in diameter - had allegedly appeared 5 years before and were localized in a well-demarcated area (fig. 1). Pressure did not provoke pain. Previous treatments with topical steroids, prescribed elsewhere on the basis of the clinical presentation, had proved ineffective.

A skin biopsy showed acanthosis in the epidermis, suprabasal dyskeratosis, and acantholysis, with clefts over the papillary dermis, covered by a single layer of epithelium. Dyskeratotic cells with irregular pyknotic nuclei surrounded by a bright eosinophilic halo were seen in the stratum granulosum, while the stratum corneum presented with so-called grains (i.e. multiple, compressed cells with elongated nuclei and many keratohyaline granules) (fig. 2).

\section{Discussion}

Darier's disease (DD), also called 'Darier-White disease' or 'dyskeratosis follicularis', is an autosomal dominant inherited genodermatosis with high penetrance (95\%) and an incidence of 1:36,000-100,000 per year [1]. A mutation in the ATP2A2 gene at locus $12 \mathrm{q} 23-24$, which codes for SERCA2, a calcium pump channel of the endoplasmic reticulum involved in adhesion and differentiation processes of epithelial cells, has been identified [2]. In the majority of cases, the disease manifests in adolescents or young adults with small brownishyellow, warty, hyperkeratotic papules in the seborrheic areas of the body, such as the scalp, retroauricular and temporal areas, back of the neck, anterior trunk, and folds; the palms, soles, nails, and mucosae can also be involved. Lesions tend to coalesce into thicker, greasy plaques which, in folds, may macerate, become infected, and smell unpleasantly. In $80 \%$ of the cases, moderate-to-severe itch is reported [3].

Localized DD (LDD) is a clinical variant, first described by Kreibich in 1906 [4], usually presenting a zosteriform, linear, or segmental distribution and, in $10 \%$ of the cases, situated along the Blaschko lines $[5,6]$, because of a genetic mosaicism induced by a mutation occurring during embryogenesis [7]. Only a few nonsegmentally distributed and histologically confirmed cases of LDD have been described to date; they presented in the vulva [8,9], on the mammary areolae [10], in photo-exposed areas only [11], and, in one case, ectopically in the cervix [12]. LDD seems to have a late onset and can be associated with HIV and previous radiotherapy [13]. The medical history in our patient was irrelevant, the HIV serology negative. Histology proved conclusive for LDD, since all the required pathognomonic features were present, especially dyskeratotic cells.

The patient was encouraged to avoid triggering factors such as UV exposure, heat, and trauma and to daily apply $0.1 \%$ adapalene cream, since topical retinoids had proved effective in similar cases [3]. The treatment led to complete resolution of the lesions, as well as of the itch.

\section{Statement of Ethics}

Signed consent was obtained from the patient for publication. 


\section{Disclosure Statement}

The authors declare no conflicts of interest.

\section{References}

1 Munro CS: The phenotype of Darier's disease: penetrance and expressivity in adults and children. Br J Dermatol 1992;127:126-130.

-2 Savignac M, Edir A, Simon M, et al: Darier disease: a disease model of impaired calcium homeostasis in the skin. Biochim Biophys Acta 2011;1813:1111-1117.

3 Sehgal VN, Srivastava G: Darier's (Darier-White) disease/keratosis follicularis. Int J Dermatol 2005;44:184-192.

-4 Kreibich K: Zum Wesen der Psorospermosis Darier. Arch Dermatol Syphilol (Wien) 1906;80:367.

5 Barfield RL, Barrett KR, Moon CM, David-Bajar K: Pruritic linear papules on a 75-year-old woman: a case of localized Darier-White disease. Cutis 2002;70:225-228.

-6 O'Malley MP, Haake A, Goldsmith L, et al: Localized Darier disease. Implications for genetic studies. Arch Dermatol 1997;133:1134-1138.

7 Milobratović D, Vukićević J: Localized Darier's disease. Acta Dermatovenerol Alp Pannonica Adriat 2011;20:213-215.

8 Salopek TG, Krol A, Jimbow K: Case report of Darier disease localized to the vulva in a 5-year-old girl. Pediatr Dermatol 1993;10:146-148.

-9 Barrett JF, Murray LA, MacDonald HN: Darier's disease localized to the vulva. Case Report. Br J Obstet Gynaecol 1989;96:997-999.

10 Fitzgerald DA, Lewis-Jones MS: Darier's disease presenting as isolated hyperkeratosis of the breasts. Br J Dermatol 1997;136:290.

11 Kimoto M, Akiyama M, Matsuo I: Darier's disease restricted to sun-exposed areas. Clin Exp Dermatol 2004;29:37-39.

12 Adam AE: Ectopic Darier's disease of the cervix: an extraordinary cause of an abnormal smear. Cytopathology 1996;7:414-421.

13 Emadi SN, Izadi M, Poursaleh Z, Akhavan-Moghaddam J, Barikbin B, Emadi SE: Darier disease associated with HIV infection: a case report. HIV Clin Trials 2011;12:48-53.

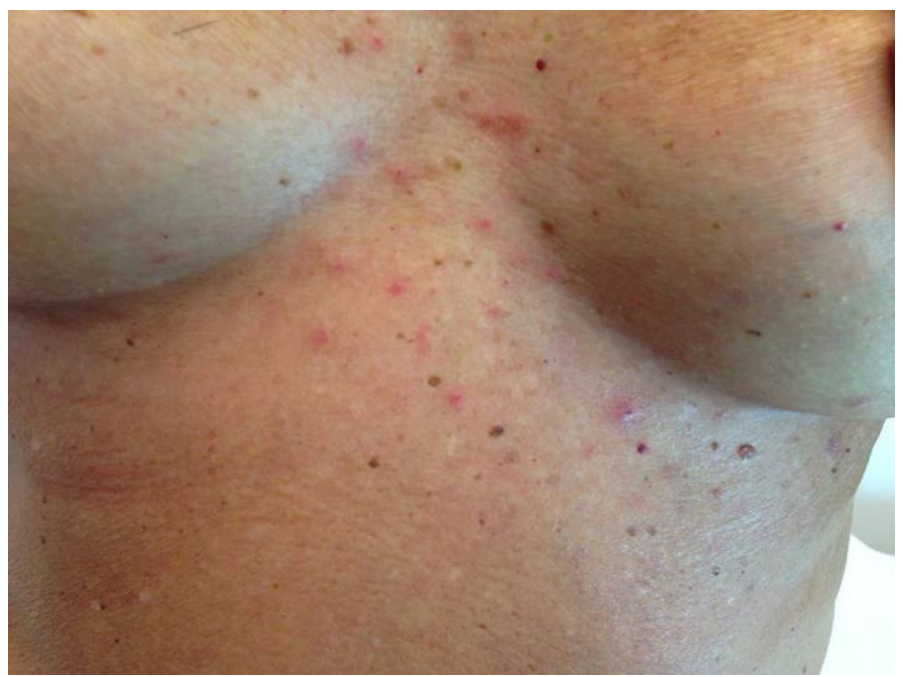

Fig. 1. Itchy red papules were noticeable in the inframammary region. 


\section{Case Reports in

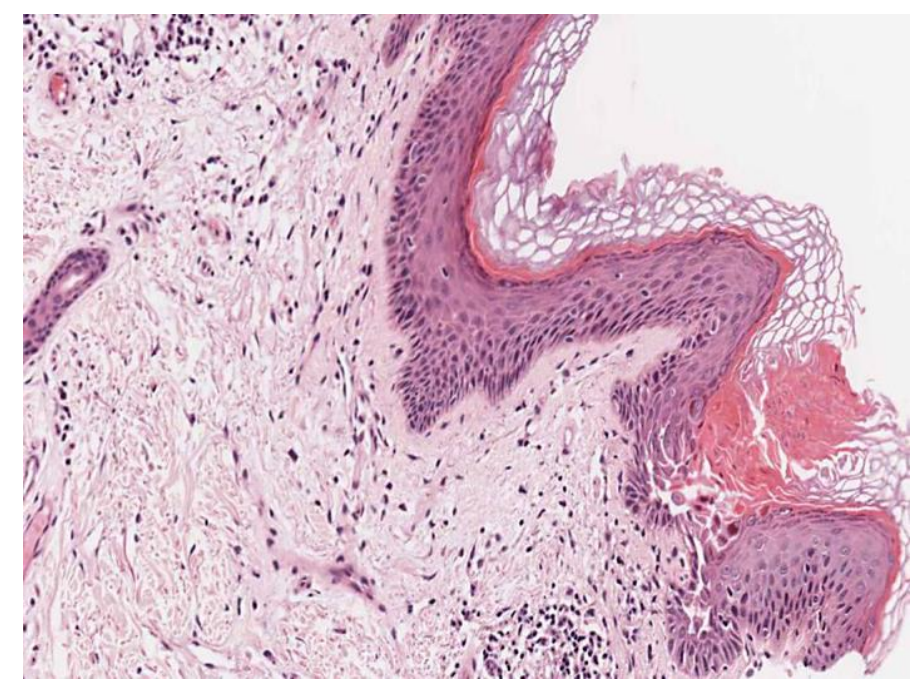

Fig. 2. Histology of the skin biopsy showed acanthosis in the epidermis, suprabasal dyskeratosis, and acantholysis, with clefts over the papillary dermis, covered by a single layer of epithelium. Dyskeratotic cells were seen in the stratum granulosum, while the stratum corneum presented with so-called grains. 